\title{
PEACOCK MODEL PEDAGOGY: INTERVENTION AND INNOVATIVE CATALYST IN THE NEW NORMAL PERSPECTIVE OF TEACHING AND LEARNING
}

\author{
LEOVIGILDO LITO D. MALLILLIN*, REGILITO D. LAUREL², PILIPINAS AMERICA C. ARROYO³, JOCELYN B. \\ MALLILLIN $^{4}$ \\ ${ }^{1}$ Consultant and Research Specialist, Quezon City, Philippines \\ ${ }^{2}$ Faculty of Education, English Department, University of Benghazi, Libya \\ ${ }^{3}$ University of Tripoli, Tripoli, Libya \\ ${ }^{4}$ San Bartolome High School, Quezon City, Philippines \\ *Email: loviedsunbright_0722@yahoo.com.ph
}

Received: 29 May 2021, Revised and Accepted: 2 August 2021

\begin{abstract}
The study aims to analyze and identify how peacock model pedagogy improves the intervention and innovation catalyst in the new normal perspective of teaching and learning among the respondents. The study employs both a descriptive quantitative and qualitative research approach and design because it is used in analysing the intervention and innovative catalyst in the new normal perspective of teaching and learning. Purposive sampling is utilized in gathering the sample size of the study. It is a selection of intentional formats based on the concept that elucidates the specific theme or phenomenon of the study. This study comprised thirty six (36) respondents. Results show that students are actively participating and developing quality of leadership and initiative and are actively participating through exchange of ideas and interactions in the peacock model pedagogy on innovation of teaching and learning, participation, with a weighted mean of 4.06 or Agree which shows that students are actively participating and developing quality of leadership and initiative and are participating actively through exchange of ideas and interactions, questioning and experimentation, with a weighted mean of 3.66 or Agree which shows that students are able to frame learning related questions and inquisitive lessons for discussion and are able to frame learning related questions but have difficulties in exploring to answer the question raised among them, empathy and cooperation, with a weighted mean of 3.75 or Agree which shows that students are empathetic towards both the known and unknown persons in the pedagogy of learning in the new normal and are actively empathetic towards the known but only sympathetic towards the unknown process of learning, aesthetic and creative expression of knowledge, with a weighted mean of 3.75 or Agree which shows that students are aesthetic and creative in their new normal learning perspective pedagogy and are aesthetic and creative in their online classes as part of their innovative learning perspective. Findings show that there is a significant difference in the peacock model pedagogy that improves the intervention and innovation catalyst in the new normal perspective of teaching and learning as observed by the respondents.
\end{abstract}

Keywords: Peacock model pedagogy, Intervention and innovation of teaching, Catalyst of teaching, Peacock model, Participation of learning, Empathy and cooperation, Aesthetic and creative expression of knowledge.

(c) 2021 The Authors. Published by Innovare Academic Sciences Pvt Ltd. This is an open access article under the CC BY license (https://creativecommons.org/licenses/by/4.0/) DOI: https://dx.doi.org/10.22159/ijoe.2021v9i6.42802. Journal homepage: https://innovareacademics.in/journals/index.php/ijoe

\section{INTRODUCTION}

Education is an institutional that serves the community for knowledge improvement and innovation. It is a sustainable, comprehensible, superb that meets the challenges and evolves the fast-changing trends in the quality of teaching and learning, especially in the new normal perspective of the educational system that is unpredictable in the globalized world. How ready is the educational system in the implementation the new normal? The trend of the educational pedagogy in online learning explores the academic designs that suit the need of the learner's competency and student development in various learning literacy on enhanced learning and collaborative technology. It provides various transitions in the new normal readiness and implementation of online learning for both students and teachers in terms of access to link to the internet, effective platform online learning, access to digital work, and online teaching school practices. Online learning in various pedagogy of learning tools and resources is based on the innovation and intervention that empowers the creative technology and creative activity that connects the learning process as an advantage among students to customize flexibility and learning process to improve dynamic technology and innovation to enhance the professional skills in the demand of the new normal teaching and learning perspective catalyst that will be helpful in the access of the online teaching practices among the learners (Mallillin, Mendoza, Mallillin, Felix, \& Lipayon, 2020). On the other hand, the educational innovation and intervention as a catalyst to the pedagogy of teaching and learning in the new normal perspective outline the direction which is potential for effective innovation to be integrated into the schools, colleges, and universities. The desired effect should be implemented and increase in the intervention and based-innovation transformation in the system of education. Innovation and intervention must be done through knowledge integration in online classes enhancement and learning of students that influences the lecturers in the technology of teaching that focuses on professional knowledge and belief in the enhancement of student learning. The innovation and intervention catalyst identifies gaps and issues in online classes in knowledge integration to enhance pedagogy of learning among students. It focuses on techniques utilized on the impact of students that deals with behavior and attitude of the learners on the knowledge integration during the online classes in the new normal perspectives. On the other hand, integration of knowledge innovation and intervention catalyst has issues in the online classes as to internet connection which is slow and weak that affect the learning process and enhancement through technology and program for virtual knowledge of learning. This distracts the students from the adoption of learning and struggles in online learning classes (Mallillin, Carag, Mallillin, \& Laurel, 2020). The systematic educational innovation provides the potential direction for effective interventions in the educational setting and integration being utilized in the schools, colleges, and universities to produce the desired effect in the increased 
transformation and innovation of the educational system pedagogy and catalyst. The intervention and innovation catalyst highlights the online efficiency and online learningintensive approaches using the peacock model of learning and pedagogy. Moreover, innovation and intervention catalyst evolution are very important and essential in the online learning classes because it plays an important role in the creation of sustainable techniques in teaching in the development of the educational system and setting that resembles the innovation mutation process to better equip the learning process. This involves the various domains of learning in the academic performance of students in the new normal or online classes. The various domains of learning are designed in the various activities based on the needs of students in their online learning classes to explore their knowledge and activities participation in in-depth subject learning. It provides to assist lecturers in their innovation of teaching intervention and catalyst based on the learning process and enhancement of students in terms of the psychomotor, affective, and cognitive domain of learning. It also identifies the extent of the learning domains and academic performance of students in the area of academic achievement, attitude, and behavior in their studies and skills of learning. It also provides the ability to uphold the lesson through proper implementation and execution in the cognitive learning to have active attention among students through proper motivation to respond and to learn and satisfy on their worth and attitude, preference, acceptance, and belief on value and commitment in the affective domain of learning that can relate to student body movement, coordination or touch, auditory, visual, and the ability to provide knowledge and information in the psychomotor domain of learning environment. The domain of learning in the performance of students in their academics acquire knowledge and skills for different situations in the learning skills of students who will participate in the different activities in the classroom especially in the behavior and attitude of students in their studies. It also focuses on the provided lesson for better results and output in the academic performance and learning process of students in the various domains of learning (Mallillin, 2020). In addition, the intervention and innovation catalyst in the new normal perspective of teaching and learning must have a framework to be followed in the online learning process and enhancement of students because it provides educational pedagogy that implements the peacock model acquisition during the shifting of the traditional classroom setting to online teaching setting. It is a pinnacle of the vision and life attitude of the learners since the process of education learning is continuous. It emphasizes the framework and analyses the process of online classes and learning guide and improvement of the tool of teaching during the new normal perspective of learning. It identifies the various frameworks in the innovation and intervention catalyst in the implementation of online teaching classes, teaching mode of delivery, support and process of the school system as a guide in the educational setting in the system during the new normal process of teaching and learning. It also introduces virtual reality design as part of the catalyst in innovation and intervention in teaching online. It possesses the potential application process in online teaching and learning in a systematic educational setting design and existence for the purpose that displays the learning process. It also supports the delivery mode, learning process, student needs, and teaching needs in the instruction and modality of online teaching and learning to improve and boost the ability and potential of students. It also provides guides in online teaching and learning for student tools in the new normal perspective (Mallillin, Mallillin, Carag, Collado, \& Largo, 2020).

The peacock model pedagogy on the intervention and innovation catalyst in the new normal perspective of teaching and learning is anchored on extrinsic and intrinsic motivation from the perspective of the Self-Determination Theory (SDT) Ryan and Deci (2020). This theory defines the practice of teaching in the new normal online classes. It is a factor that understands the broad framework on STD that undermines the facilitation of autonomous motivation as intrinsic and extrinsic in the direct relevance and issues in the educational setting. It shows that both intrinsic and extrinsic motivation are wellinternalized and predicts the positive array and outcome across the educational varied cultural context and level to support and enhance student needs in their new normal perspective learning as to psychological needs, relatedness, competence and autonomy. It provides a dynamic link for both students and teachers, motivation as teachers are constrained and impacted by mandate control, school pressures, and style of leadership. It is substantial evidence for the essential and psychological need and satisfaction of the context in learning for the practices and policies that are anchored on the motivational and traditional models in support of the student's and teacher's needs. Lastly, the introduction of the peacock model pedagogy in the intervention and innovative catalyst in the new normal perspective of teaching and learning has been given emphasis as to participation, questioning and experimentation, interpretation and application, empathy and cooperation, and aesthetic and creative expression of knowledge. It is regarded as a necessary and positive approach in online learning of students as the basis for constant needs and innovation to a sustainable educational setting and system. It is a transformation from traditional classroom teaching to online teaching, which increases the credibility and integrity of the lecturers in the new normal skills knowledge and level. It is an effective and better use of resources in teaching online. It highlights the reflection and philosophy of education in its concept and system in the modern evaluation of educational setting, especially in the new normal perspective where it adopts the PEACOCK MODEL of teaching and learning pedagogy. The peacock model is a reflection and analysis of the validity and attempted plausibility in the current system and educational setting for a comprehensive innovation and intervention catalyst and learning pedagogy in the new normal perspective of teaching and learning (Mondal, 2018). Concept of the study

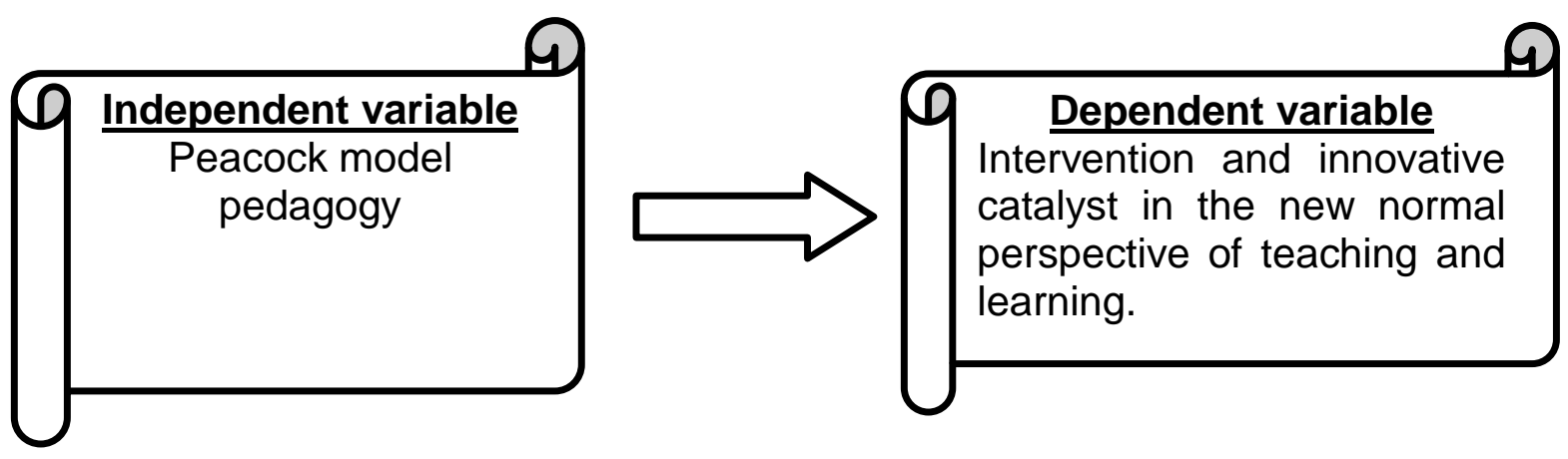

Fig. 1: Independent and dependent variables on peacock model pedagogy 


\section{RESEARCH QUESTION}

1. How does peacock model pedagogy improve the intervention and innovation catalyst in the new normal perspective of teaching and learning among the respondents?

2. Is there a significant difference in the peacock model pedagogy that improves the intervention and innovation catalyst in the new normal perspective of teaching and learning as observed by the respondents?

\section{HYPOTHESIS}

There is a significant difference in the peacock model pedagogy that improves the intervention and innovation catalyst in the new normal perspective of teaching and learning as observed by the respondents.

\section{METHODOLOGY}

The study employs both descriptive quantitative and qualitative research approaches and design. Quantitative research is used in analysing the intervention and innovative catalyst in the new normal perspective of teaching and learning. It establishes and generalizes the facts about the study. Quantitative research design is adopted the immersive virtual reality in the method and educational pedagogy that focuses on the learning outcome, characteristics, intervention and measures the assessment of the systematic interpretation and utility of the study, which is essential in the potential understanding of the pedagogical method, (Hamilton, McKechnie, Edgerton, \& Wilson, (2021). On the other hand, qualitative research expresses the words to understand the concept, thought, and experiences to gather the topics and indepth observation that explores the theory on the peacock model pedagogy as to participation, questioning and experimentation, interpretation and application, empathy and cooperation, and aesthetic and creative expression of knowledge. It generalizes the goals and features of the qualitative research as to the application of the advanced integral knowledge that describes the trustworthiness of the strategy and criteria in maximizing the study as to theory, approach, meta-synthesis, and content analysis of the findings (Hays \& McKibben, 2021).

Participants of the study

The participants of the study are the professional lecturers in Commission on Higher Education (HEIs), both private and public educational institutions in the Philippines. The participants are knowledgeable in the topic that can give a better result and output of the study. The questionnaire is sent via google form and whoever answers the questionnaire will be counted as participants-the study comprised thirty six (36) respondents only.

\section{Sampling techniques}

Purposive sampling is utilized in gathering the sample size of the study. It is a selection of intentional formats based on the concept that elucidates the specific theme or phenomenon of the study. It involves the process and iterative research selection in predetermined criteria and frame samples. It involves the process of identifying concepts and themes as indicators of the reflection and observation of the study. It provides emphasis on the particular samples occupying the relative endeavor and position. It also utilizes the techniques and purpose sampling in particular knowledge, experience, focus and empirical inquiry. On the other hand, purposive sampling is a development history and its simple and straightforward complexity in improving the rigor and trustworthiness of the results of data as to concept and aspect of the research confirmability, credibility, dependability, and transferability. It outlines the intent and nature of purposive sampling and examples of different applications and contexts (Campbell et al., 2020, p. 8).

Instrument used

Innovation and intervention catalyst in the new normal perspective teaching and learning

\begin{tabular}{|c|c|l|}
\hline Scale & Descriptive level & \multicolumn{1}{|c|}{ Descriptive interpretation } \\
\hline $4.20-5.00$ & Strongly agree & Innovation and intervention catalyst of teaching is extremely satisfied \\
\hline $3.40-4.19$ & Agree & Innovation and intervention catalyst of teaching is very satisfied \\
\hline $2.60-3.39$ & Moderately agree & Innovation and intervention catalyst of teaching is limited \\
\hline $1.80-2.59$ & Disagree & Innovation and intervention catalyst of teaching is slightly satisfied \\
\hline $1.00-1.79$ & Strongly disagree & Innovation and intervention catalyst of teaching is not satisfied at all \\
\hline
\end{tabular}

\section{RESULTS}

Table 1: Peacock model pedagogy on the intervention and innovation catalyst in the new normal perspective of teaching and learning among the respondents

\begin{tabular}{|c|c|c|c|}
\hline Indicators & WM & I & $\mathbf{R}$ \\
\hline Students are actively participating and developing the quality of leadership and initiative. & 4.03 & A & 1.5 \\
\hline Students are able to frame learning-related questions and inquisitive lessons for discussion. & 3.66 & A & 8 \\
\hline Students are able to explain the related ideas with examples and the application of the lesson. & 3.75 & A & 3.5 \\
\hline $\begin{array}{l}\text { Students are empathetic towards both the known and unknown persons in the pedagogy of learning in the } \\
\text { new normal. }\end{array}$ & 3.75 & A & 3.5 \\
\hline Students are aesthetic and creative in their new normal learning perspective pedagogy. & 3.72 & A & 5.5 \\
\hline $\begin{array}{l}\text { Students are less eager for aesthetic and creative activities in their new normal learning perspective } \\
\text { pedagogy. }\end{array}$ & 3.16 & MA & 19 \\
\hline $\begin{array}{l}\text { Students are not expressive and empathized in their innovation and pedagogy of learning in the new } \\
\text { normal perspective. }\end{array}$ & 3.19 & MA & 16.5 \\
\hline Students can only interpret and cram the related idea of the lesson. & 3.19 & MA & 16.5 \\
\hline $\begin{array}{l}\text { Students are asked questions, but those are not helpful in learning-related inquisition for the learning } \\
\text { pedagogy. }\end{array}$ & 3.25 & MA & 14 \\
\hline Less eager to participate in the entire discussion during their online classes. & 3.16 & MA & 19 \\
\hline Students are participating but not willing to interact in the discussion online. & 3.66 & A & 8 \\
\hline Students are not asked frame learning-friendly related questions but inquisitive for a healthy discussion. & 3.31 & MA & 11.5 \\
\hline $\begin{array}{l}\text { Students are able to partially explain the related ideas with examples but unable to apply the learning } \\
\text { process. }\end{array}$ & 3.31 & MA & 11.5 \\
\hline Students are sympathetic towards the known persons in the innovation and intervention of learning. & 3.59 & A & 10 \\
\hline Students are eager for aesthetic and creative activities in their new normal learning perspective pedagogy. & 3.72 & A & 5.5 \\
\hline
\end{tabular}


Innovare Journal of Education, Vol 9, Issue 6, 2021, 7-15

\begin{tabular}{|c|c|c|c|}
\hline Indicators & WM & I & $\mathbf{R}$ \\
\hline Students are aesthetic and creative in their online classes as part of their innovative learning perspective. & 3.66 & A & 8 \\
\hline $\begin{array}{l}\text { Students are actively empathetic towards the known but only sympathetic towards the unknown process of } \\
\text { learning }\end{array}$ & 3.25 & MA & 14 \\
\hline Students are able to explain the related ideas with examples but are unable to apply the learning process. & 3.16 & MA & 19 \\
\hline $\begin{array}{l}\text { Students are able to frame learning-related questions but have difficulties in exploring to answer the } \\
\text { question raised among them. }\end{array}$ & 3.25 & MA & 14 \\
\hline Students are participating actively through the exchange of ideas and interactions. & 4.03 & A & 1.5 \\
\hline Average weighted mean & 3.49 & A & \\
\hline Standard deviation & 0.30 & & \\
\hline
\end{tabular}

Note: WM-refers to the weighted mean to measure the holistic point of view of the response of the respondents, I-refers to the interpretation of the answer of the respondents, R-refers to the ranking to show the order of the answer of the respondents, A-refers to agree; MA- refers to moderately agree

Table 1 presents the weighted mean and the corresponding interpretation of peacock model pedagogy on intervention and innovation catalyst in the new normal perspective of teaching and learning among the respondents. As observed in the table, rank 1 is shared by the two indicators, which are "Students are actively participating and developing the quality of leadership and initiative" and "Students are participating actively through the exchange of ideas and interactions," with a weighted mean of 4.03 or Agree. This shows that innovation and intervention of the peacock model pedagogy are observed. Rank 2 is also shared by the two indicators, which are "Students are able to explain the related ideas with examples and application of the lesson" and "Students are empathetic towards both the known and unknown persons in the pedagogy of learning in the new normal," with a weighted mean of 3.75 or Agree. This shows that innovation and intervention of the peacock model pedagogy in this area are observed. Rank 3 is also shared by the two indicators, which are "Students are aesthetic and creative in their new normal learning perspective pedagogy" and "Students are eager for aesthetic and creative activities in their new normal learning perspective pedagogy," with a weighted mean of 3.72 or Agree. This shows that innovation and intervention of the peacock model pedagogy in this area are observed. The least in rank is shared by the three indicators, which are "Students are less eager for aesthetic and creative activities in their new normal learning perspective pedagogy," "Less-eager to participate in the entire discussion during their online classes," and "Students are able to explain the related ideas with examples but are unable to apply the learning process," with a weighted mean of 3.16 or Moderately Agree. This shows that innovation and intervention of the peacock model pedagogy are limited. The overall weighted mean is 3.49 or Agree which means that peacock model pedagogy in the innovation and intervention catalyst in the new normal perspective of teaching and learning is observed among the respondents.

Table 2: Significant difference on the peacock model pedagogy as observed by the respondents

\begin{tabular}{|l|c|c|c|c|}
\hline \multicolumn{1}{|c|}{ Model } & Z computed value & Comparison & Z critical value & Decision \\
\hline Peacock model pedagogy as observed by the respondents & 38.23 & $>$ & \pm 1.96 & Rejected \\
\hline Two-tailed test with level of significance at 0.05 level
\end{tabular}

Table 2 shows the significant difference in the peacock model pedagogy that improves the intervention and innovation catalyst in the new normal perspective of teaching and learning. It reveals in the table that when the variables are computed, it shows that $\mathrm{z}$ commuted value of 38.23 is higher than the $\mathrm{z}$ critical value of \pm 1.96 , which resulted in the decision of rejection in the null hypothesis. Therefore, it is safe to say that there is a significant difference in the peacock model pedagogy that improves the intervention and innovation catalyst in the new normal perspective of teaching and learning as observed by the respondents. The alternative hypothesis is accepted.

Table 3: Thematic analysis and core ideas on the peacock model pedagogy

\begin{tabular}{|c|c|c|}
\hline Theme peacock model & Frequency of responses & Core ideas \\
\hline Participation & $\begin{array}{l}\text { General } \\
\text { General } \\
\text { Typical } \\
\text { Variant }\end{array}$ & $\begin{array}{l}>\text { Development quality of leadership and initiative } \\
>\quad \text { Exchange of ideas and interactions } \\
>\quad \text { Online discussion and interaction } \\
>\text { Less-eager to participate }\end{array}$ \\
\hline Questioning and experimentation & $\begin{array}{l}\text { General } \\
\text { Variant } \\
\text { Variant } \\
\text { Variant }\end{array}$ & $\begin{array}{ll}> & \text { Frame related question/inquisitive } \\
> & \text { Difficulties in exploring questions } \\
> & \text { Inquisitive question for healthy discussion } \\
> & \text { Related question learning pedagogy }\end{array}$ \\
\hline Interpretation and application & $\begin{array}{l}\text { Variant } \\
\text { Variant } \\
\text { Typical } \\
\text { Typical }\end{array}$ & $\begin{array}{l}>\quad \text { Explain the example of lessons } \\
>\quad \text { Apply the learning process } \\
>\quad \text { Related ideas of the lesson } \\
>\quad \text { Emphasis of innovation and pedagogy }\end{array}$ \\
\hline Empathy and cooperation & $\begin{array}{l}\text { Typical } \\
\text { Variant } \\
\text { Typical } \\
\text { Variant }\end{array}$ & $\begin{array}{ll}> & \text { Pedagogy learning empathy } \\
> & \text { Sympathy on the learning process } \\
> & \text { Innovation and intervention of learning } \\
> & \text { Expressive pedagogy of learning }\end{array}$ \\
\hline
\end{tabular}


Innovare Journal of Education, Vol 9, Issue 6, 2021, 7-15

\begin{tabular}{|l|c|c|}
\hline \multicolumn{1}{|c|}{ Theme peacock model } & Frequency of responses & \multicolumn{1}{c|}{ Core ideas } \\
\hline & Typical & $>\quad$ Creative and aesthetic pedagogy of learning \\
Aesthetic and creative expression & Typical & $>$ Online classes innovation \\
of knowledge & General & Aesthetic and creative activities \\
& Variant & Less aesthetic and creative activities \\
\hline
\end{tabular}

\section{Participation}

Participation in the innovation and intervention catalyst in the new normal perspective teaching and learning focuses and emphasizes on the process and product of systematic pedagogy and genre in the teacher's development practices in the cycle of teaching and learning. Participation in terms of professional development and collaboration in support that illustrates the pedagogy of students' needs (Brisk, Tian, \& Ballard, 2021). Generally, the respondents say that:

"Students are actively participating and developing the quality of leadership and initiative." (P16, P9-T1)

"Students are participating actively through the exchange of ideas and interactions." (P15, P10-T1)

"Students are participating but not willing to interact in the discussion online."(P11, P13-T1)

"Less-eager to participate in the entire discussion during their online classes." (P7, P14-T1)

Questioning and experimentation

Questioning and experimentations are deemed and necessary in the learning pedagogy to enhance innovation in teaching. It promotes the program and sustainable experimentation inequitable participation, interest and initiative. It transforms and responds to the principles and strategy in teaching, especially in the new normal perspectives in education. It provides a sustainable classroom pursuit in the engagement of the creative material and demonstrates the impact of the visual initiative in teaching outcome and experiment in a dynamic power of the school-based learning and self-organized learning and activity (Hector \& Kohtala, 2021). The participants observed that:

"Students are able to frame learning-related questions and inquisitive lessons for discussion." (P17, P6-T2)

"Students are able to frame learning-related questions but have difficulties in exploring to answer the question raised among them." (P9, P17-T2)

"Students are not asked frame learning-friendly related questions but inquisitive for a healthy discussion." (P10, P14-T2)

"Students are asked questions, but those are not helpful in learning-related inquisition for the learning pedagogy." (P9, P12-T2)

\section{Interpretation and application}

Interpretation and application of innovation and intervention catalyst in the new normal teaching and learning of students identify the influences and factors of various teaching strategies in the academic context of learning. It carries the structural design of pedagogy of teaching and learning obtained in the peacock model and tool innovation that influences the teaching positively. It advances and contributes to the elaboration and practices of students centered learning, which is highlighted in the application of the model (Pinho, Franco, \& Mendes, 2021). Typically, the participants express that: "Students are able to explain the related ideas with examples and application of the lesson." (P13, P10-T3)

"Students are able to explain the related ideas with examples but are unable to apply the learning process." (P9, P13-T3)

"Students are able to partially explain the related ideas with examples but unable to apply the learning process." (P5, P17-T3) "Students can only interpret and cram the related idea of the lesson." (P7, P17-T3)

\section{Empathy and cooperation}

Empathy and cooperation in the catalyst of innovation and intervention in the new normal perspective of teaching and learning respond to the learning diversity of students. It provides the process and methods of various transformations in the pedagogy of teaching-based models in cooperation with students and teachers. It is a journey made from traditional teaching to online teaching courses in the classroom action and implementation of cooperative learning methods of teaching and perspective. It analyses the action and process of the teacher's technique in teaching and observation. It transforms the improvement in teaching and practices based on the cooperative learning method of teaching support and involvement in continuous training in the quality of education among teachers and students (Muñoz-Martínez, GárateVergara, \& Marambio-Carrasco, 2021). Typically, the participants emphasize that:

"Students are empathetic towards both the known and unknown persons in the pedagogy of learning in the new normal." (P15, P8-T4)

"Students are actively empathetic towards the known but only sympathetic towards the unknown process of learning." (P9, P16-T4)

"Students are sympathetic towards the known persons in the innovation and intervention of learning." (P13, P4-T4)

"Students are not expressive and empathized in their innovation and pedagogy of learning in the new normal perspective." (P7, P17-T4)

\section{Aesthetic and creative expression of knowledge}

Aesthetic creativity and experience overlap the process in the conscious cognitive practice in teaching that designs and focuses on the enhanced and creative, effective learning and perspective in the new normal. It provides a better effect and understanding of the controlled practice and intervention on the innovation catalyst and pedagogy of teaching and learning. It facilitates the best creativity of learning among students. It provides experience in a design aesthetic and creativity that examines the teaching and learning of the present new normal situation in the educational setting through association, life experience, perception analysis, function analysis, and emotion aesthetic creativity evocation. The engagement of the stimuli intervention practices contributes to the analytical enhancement thinking of the learners for creative improvement that influences the learning effect, innovation, and intervention (Yeh, Hsu, \& Yastrubinskiy, 2021). Typically, the participants emphasized that:

"Students are aesthetic and creative in their new normal learning perspective pedagogy." (P16, P8-T5)

"Students are aesthetic and creative in their online classes as part of their innovative learning perspective." (P15, P5-T5)

"Students are eager for aesthetic and creative activities in their new normal learning perspective pedagogy." (P16, P6-T5)

"Students are less eager for aesthetic and creative activities in their new normal learning perspective pedagogy." (P7, P15-T5)

\section{DISCUSSION}

The peacock model pedagogy provides a framework on intervention and innovation catalyst in the new normal perspective of teaching and learning among the respondents. It shows that students are actively participating and developing the quality of leadership and initiative in their online learning classes. Likewise also that students are participating actively through the exchange of ideas and interactions, which are essential in the discussion during their online lesson. It shows that students are able to explain the related ideas with examples and application of the lesson and are empathetic towards both the known and unknown knowledge in the pedagogy of learning in the new normal which the model of peacock pedagogy is observed. Hence, students are aesthetic and creative in their new normal learning perspective 
pedagogy and eager for aesthetic and creative activities. On the other hand, students who are less eager for aesthetic and creative activities in their new normal learning perspective pedagogy were eager to participate in the entire discussion during their online classes. They are able to explain the related ideas with examples but are unable to apply the learning process. Hence, peacock model pedagogy promotes innovation in the teaching and learning tools for both lecturers and teachers in the integration of management and teaching design curriculum and assessment technology pedagogy and strategy (Ellis \& Goodyear, 2019). Moreover, results of participation on peacock model pedagogy on intervention and innovation in the new normal perspective in teaching and learning develops and participates actively their students in their quality of leadership and initiatives where it analyses the leading catalyst of students in their leadership quality and initiative to define better student in their curricular change and leadership on their role in broadening student leadership, empowerment and success recognition beyond educational passive and consumption, (Burk-Rafel et al., 2020). It also shows that students are actively participating through exchange interaction and ideas where it remains an issue on various modules and subject challenges in the online classroom teaching. It involves various activities in adopting the roles that focus on the interactive lessons on learners' needs, support and practice (Wieselmann, Dare, Ring-Whalen, \& Roehrig, 2020). On the other hand, it also shows that students are not willing to interact and participate in the online discussion where it results in both lesser or eager participation depending on the mood of students in their online classes and discussions. It demonstrates the behavioral and motivational process that explains among students in the new normal learning enhancement than face-to-face courses as well as their online courses. There is a need to create a flexible competing responsibility and performance of students in the academic activities, and implication of control effect selection and characteristic (McPartlan, Rutherford, Rodriguez, Shaffer, \& Holton, 2021). On the other hand, the result of the questioning and experimentation on the peacock model pedagogy in the innovation and intervention of the new normal perspective teaching and learning emphasized that students are able to frame learning related to inquisitive and question lessons for discussion where questioning is based on the student needs and materials of learning in a valuable lesson and assistance. It develops and aims in the interactive evaluation of learning materials to equip in the improvement of skills, critical thinking, and effectiveness of students (Djamas, Tinedi, \& Yohandri, 2021). It also shows that students are able to frame learning-related questions but have difficulties in exploring to answer the question raised among them. This is where the art of questioning will be given emphasis to motivate students in their learning process, especially during their online classes. Questions given to students must explore the critical thinking, resourcefulness, and power to understand the lesson in their module. They need to understand these techniques for better learning output (Willingham, 2021). Hence, it also shows that students are not asked frame learning-friendly related questions but inquisitive for a healthy discussion. This will help students to increase their belief, attitude and knowledge about the lesson to be discussed and behavior capability on selflearning and efficacy. It determines the effectiveness of the questions being raised that motivates and boosts the morale of students in their learning process, which is effective and improves the capacity and ability of students in their studies (Kulik et al., 2019). It also reveals that students are asked questions but those are not helpful in learning-related inquisition for the learning pedagogy where learning processes are provided even during their orientation at the start of their online classes even their lecturers that provide scientific, educational integration process that involves interaction among the learners as to their leading learning, elaboration, and inquisition result (Hongyan, 2018). Furthermore, the result of interpretation and application on the peacock model pedagogy of innovation and intervention of the new normal perspective teaching and learning shows students are able to explain the related ideas with examples and application of the lesson where it examines the learning differences of the learners who are provided instructions and examples in their online lessons on key concepts. It analyses the modeled outcome in the moderated effect and creates lessons for student's clarification and assistance (Bolkan \& Goodboy, 2019). Hence, students are able to explain the related ideas with examples but are unable to apply the learning process due to the growth and rapid technology and computer learning integrated with intelligence techniques to develop a personalized system of education. The system and performance of the learners and experiences are interfaces and designed for the learning enhancement in the new normal of educational existence and system at present (Mousavinasab et al., 2021). Besides, students are able to partially explain the related ideas with examples but unable to apply the learning process where resources and attention are accounted for through focal and task resources and examples presented in the lesson online as application and interpretation of the learning process. It interferes with the task and performance requires resources and attention to improve the depth and automated performance of students. It explicits and implicit the learner's prediction in providing novel evidence indicated in the attention and collaboration performance of the learners (Brosowsky, Murray, Schooler, \& Seli, 2021). Likewise, students can only interpret and cram the related idea of the lesson where skills, decision making and interpretation are observed with respect to the management events in the online lesson. It also focuses on student learning and instruction context (Stahnke \& Blömeke, 2021).

Consequently, the result of empathy and cooperation on the peacock model pedagogy in the intervention and innovation of the new normal perspective teaching and learning shows that students are empathetic towards both the known and unknown persons in the pedagogy of learning in the new normal brought by the challenges and extraordinary covid crises in the educational sectors that plans and implements the procedures for the new normal educational system to sustain the educational context in the quality of education despite the modality of learning in consideration of implementation and planning of the policy in the new normal of the educational system. It responds to the challenges, issues, trends, problems in the educational norm (Tria, 2020). Also, students are actively empathetic towards the known but only sympathetic towards the unknown process of learning where it expands the implementation and identifies the critical education in practice as a constraint in the characterized policy practices in the new normal perspective of teaching and learning. It represents and generates the practices and dispositions of lecturers and strategic practice and implications in the new normal process (Rodriguez, Monreal, \& Howard, 2020). It is noted that students are sympathetic towards the known persons in the innovation and intervention of learning where independent learning is experienced among the students. It is indeed a challenge in the educational system to design the learning curriculum and to motivate and encourage independent learning to equip students online (Tan, 2021). In addition, students are not expressive and empathized in their innovation and pedagogy of learning in the new normal perspective that impacted the educational system. It explores the augment and possible learning and development holistic on various educational institutions in leveraging the emotional intelligence practices and strategies in assisting the learning development in the new normal perspective of teaching. It illustrates the skills suitability competency to adapt and cope with the needs of the learners in the new normal (Warrier, John, \& Warrier, 2021). Lastly, the result of aesthetic and creative expression of knowledge in the innovative and intervention in the new normal perspective of teaching and learning shows that students are aesthetic and creative in their new normal learning perspective pedagogy where they are successful in their learning process as regards to the implementation and description of the lesson. References and 
perspectives are made on the process and instruments on the knowledge and implication of the learning, integration and impact, (Avgerinou, 2021). Hence, it also shows that students are aesthetic and creative in their online classes as part of their innovative learning perspective. It helps students to advocate their thinking order and skills on the essential cultivation and innovation of the student's learning process. It indicates that creativity and aesthetics provide positive influences on the perceived innovation in the courses and deliveries of the students (Barak \& Yuan, 2021). On the other hand, students are eager for aesthetic and creative activities in the new normal learning perspective pedagogy that improves the achievement of the students in their potential success and creativity development in the modern education and learning in the challenges and context of knowledge advocate and application of their aesthetic innovation and exploration, (Hau, Cuong, \& Tinh, 2020). It also shows that students are less eager for aesthetic and creative activities in the new normal learning perspective pedagogy because of the transition of the learning atmosphere from traditional to the online learning process. Therefore, it is important to explore the pedagogy of the different approaches to the learning process among students especially on the intended goals and motivation that integrates on the learning of students (Franklin et al., 2020, pp. 14-24).

\section{CONCLUSION}

1. It shows that students are actively participating and developing the quality of leadership and initiative and are actively participating through the exchange of ideas and interactions in the peacock model pedagogy on the innovation of teaching and learning

2. In terms of participation, it shows that students are actively participating and developing the quality of leadership and initiative and are participating actively through the exchange of ideas and interactions.

3. In terms of questioning and experimentation, it shows that students are able to frame learning-related questions and inquisitive lessons for discussion and are able to frame learning-related questions but have difficulties in exploring to answer the question raised among them.

4. In terms of empathy and cooperation, it shows that students are empathetic towards both the known and unknown persons in the pedagogy of learning in the new normal and are actively empathetic towards the known but only sympathetic towards the unknown process of learning.

5. In terms of aesthetic and creative expression of knowledge, it shows that students are aesthetic and creative in the new normal learning perspective pedagogy and are aesthetic and creative in their online classes as part of their innovative learning perspective.

\section{Recommendation}

1. Peacock model pedagogy on the intervention and innovation catalyst in the new normal perspective of teaching and learning must be imposed because students are less eager for aesthetic and creative activities in the new normal learning perspective pedagogy since students are able to explain the related ideas with examples but are unable to apply the learning process.

2. Participation among students must be encouraged and must be imposed by the lecturers because students are participating but not willing to interact in the discussion online and are less eager to participate in the entire discussion during their online classes.

3. Questioning and experimentation must be explored by the lecturers since students are asked questions but are not helpful in learning-related inquisition for the learning pedagogy and are able to frame learning-related questions but have difficulties in exploring to answer the question raised among them. Art of questioning must be implemented properly for the innovation of the teaching and learning process.

4. Interpretation and application must be emphasized among the lecturers since students are able to explain the related ideas with examples but are unable to apply the learning process and can only interpret and cram the related idea of the lesson.
5. Empathy and cooperation must be encouraged since students are sympathetic towards the known persons in the innovation and intervention of learning and are not expressive and empathized in their innovation and pedagogy of learning in the new normal perspective.

6. Aesthetic and creative expression of knowledge must be given emphasis and must be explored by the lecturers because students are aesthetic and creative in their online classes as part of their innovative learning perspective and are less eager for aesthetic and creative activities in their new normal learning perspective pedagogy.

\section{ACKNOWLEDGEMENT}

The researchers would like to express their thanks and appreciation for the success of the research:

- To their family and loved ones for their support financially and emotionally to make this research possible.

- To the Commission on Higher Education Institutions (HEIs) for allowing the researchers to float the questionnaires among the respondents as basis for the data gathering.

- To the respndents for giving their time to go over the questionnaire and answer to their own knowledge.

- And to all the people behind the success of this research.

\section{AUTHORS CONTRIBUTIONS}

This is a collaborative effort among the members of the group where individuals have their own contribution to the success of this research.

Leovigildo Lito D. Mallillin was assigned to formulate the questionnaire, which is responsible for the floating and the validation process and also responsible for the editing and formatting of the manuscript.

Pilipinas America Arroyo was assigned to be the encoder, who is responsible for all the gathering of the data from the beginning to the end process of the data.

Regilito Laurel was assigned for the statistical treatment of the data to make a success of the concrete analysis of the data. Jocelyn B. Mallillin was responsible for the gathering of the related literature and studies in the research.

\section{CONFLICT OF INTEREST}

None.

\section{FUNDING SOURCE}

This research is non-funded.

\section{REFERENCES}

- Avgerinou, M. D. (2021). The i2flex evolution: From learning methodology to school culture embracing the new normal. In Handbook of research on $k-12$ blended and virtual learning through the i2flex classroom model (pp. 216-236). IGI Global. doi:10.4018/978-1-7998-77608.ch013

- Barak, M., \& Yuan, S. (2021). A cultural perspective to project-based learning and the cultivation of innovative thinking. Thinking Skills and Creativity, 39(1), 100766. doi:10.1016/j.tsc.2020.100766

- Bolkan, S., \& Goodboy, A. K. (2019). Examples and the facilitation of student learning: Should instructors provide examples or should students generate their own? Communication Education, 68(3), 287-307. doi:10.1080/03634523.2019.1602275

- $\quad$ Brisk, M. E., Tian, Z., \& Ballard, E. (2021). Autobiography writing instruction: The journey of a teacher participating in a systemic functional linguistics genre pedagogy professional development. (2021). System, 97, 102429. doi.org/10.1016/j.system.2020.102429 
- $\quad$ Brosowsky, N. P., Murray, S., Schooler, J. W., \& Seli, P. (2021). Attention need not always apply: Mind wandering impedes explicit but not implicit sequence learning. Cognition, 209, 104530 . doi:10.1016/j.cognition.2020.104530

- $\quad$ Burk-Rafel, J., Harris, K. B., Heath, J., Milliron, A., Savage, D. J., \& Skochelak, S. E. (2020). Students as catalysts for curricular innovation: A change management framework. Medical Teacher, 42(5), 572-577. doi:10.1080/0142159X.2020.1718070

- Campbell, S., Greenwood, M., Prior, S., Shearer, T., Walkem, K., Young, S., \& Walker, K. (2020). Journal of Research in Nursing, 25(8), 652-661. doi:10.1177/1744987120927206

- $\quad$ Djamas, D., Tinedi, V., \& Yohandri (2021). Development of interactive multimedia learning materials for improving critical thinking skills. Research anthology on developing critical thinking skills in students (pp. 507-525). IGI Global. doi:10.4018/978-1-7998-3022-1.ch026

- $\quad$ Ellis, R. A., \& Goodyear, P. (2019). The education ecology of universities: Integrating learning, strategy and the academy. UK: Routledge.

- $\quad$ Franklin, D., Coenraad, M., Palmer, J., Eatinger, D., Zipp, A., Anaya, M., ... Weintrop, D. (2020). An analysis of usemodify-create pedagogical approach's success in balancing structure and student agency. In Proceedings of the 2020 ACM Conference on International Computing Education Research (pp. 14-24), Dunedin, New Zealand: Association for Computing Machinery New York NY United States. Retrieved from https://dl.acm.org/doi/abs/10.1145/3372782.3406256

- Hamilton, D., McKechnie, J., Edgerton, E., \& Wilson, C. (2021). Immersive virtual reality as a pedagogical tool in education: A systematic literature review of quantitative learning outcomes and experimental design. Journal of Computers in Education, 8(1), 1-32. doi:10.1007/s40692020-00169-2

- Hau, N. H., Cuong, T. V., \& Tinh, T. T. (2020). Students and teachers 'perspective of the importance of arts in steam education in Vietnam. Journal of Critical Reviews, 7(11), 666-671. doi:10.31838/jcr.07.11.121

Hays, D. G., \& McKibben, W. B. (2021). Promoting rigorous research: Generalizability and qualitative research. Journal of Counseling \& Development, 99(2), 178-188. doi:10.1002/jcad.12365

- Hector, P., \& Kohtala, C. (2021). Experimenting with sustainability education: the case of a student-driven campus initiative in Finland. Local Environment, 1-16. doi:10.1080/13549839.2021.1891033

- Hongyan, Z. H. O. U. (2018). Management of university factors to support lifelong learning of faculty members (Doctoral thesis, Dhurakij Pundit University, Bangkok, Thailand). $\quad$ Retrieved from http://libdoc.dpu.ac.th/thesis/Hongyan.Zho.pdf

- Kulik, N. L., Moore, E. W., Centeio, E. E., Garn, A. C., Martin, J. J., Shen, B., ... \& McCaughtry, N. (2019). Knowledge, attitudes, self-efficacy, and healthy eating behavior among children: Results from the Building Healthy Communities trial. Health Education \& Behavior, 46(4), 602-611. doi:10.1177/1090198119826298

- Mallillin, L. L. D. (2020). Different domains in learning and the academic performance of the students. Journal of Educational System, 4(1), 1-11. Retrieved from https://www.sryahwapublications.com/journal-ofeducational-system/pdf/v4-i1/1.pdf

- $\quad$ Mallillin, L. L. D., Carag, E. A., Mallillin, J. B., \& Laurel, R. D. (2020). Integration of knowledge through online classes in the learning enhancement of students. European Journal of Open Education and E-learning Studies, 5(1), 19 34. doi:10.46827/ejoe.v5i1.3117

- $\quad$ Mallillin, L. L. D., Mallillin, J. B., Carag, E. A., Collado, J. B., \& Largo, M. G. D. (2020). A framework in online learning process: A guide to educational teaching during COVID 19 pandemic. European Journal of Open Education and Elearning Studies, 5(2), 1-15. doi:10.46827/ejoe.v5i2.3274.

- Mallillin, L. L. D., Mendoza, L. C., Mallillin, J. B., Felix, R. C., \& Lipayon, I. C. (2020). Implementation and readiness of online learning pedagogy: A transition to COVID 19 pandemic. European Journal of Open Education and E$\begin{array}{lll}\text { learning } \quad \text { Studies, } & \text { 71-90. }\end{array}$ doi:10.46827/ejoe.v5i2.3321

- $\quad$ McPartlan, P., Rutherford, T., Rodriguez, F., Shaffer, J. F., \& Holton, A. (2021). Modality motivation: Selection effects and motivational differences in students who choose to take courses online. The Internet and Higher Education, 49, 100793. doi:10.1016/j.iheduc.2021.100793

- Mondal, G. C. (2018). Reflection of Gandhian thoughts in the peacock model of continuous and comprehensive evaluation adopted in West Bengal. International Journal of Research and Analytical Reviews, 5(4), 219-233. Retrieved

from https://www.researchgate.net/publication/329628800_ REFLECTION_OF_GANDHIAN_THOUGHTS IN_THE_PEACO CK_MODEL_OF_CONTINUOUS_AND_COMPREHENSIVE_EV ALUATION_ADOPTED_IN_WEST_BENGAL

- Mousavinasab, E., Zarifsanaiey, N., Niakan Kalhori, S. R., Rakhshan, M., Keikha, L., \& Saeedi, G. M. (2021). Intelligent tutoring systems: A systematic review of characteristics, applications, and evaluation methods. Interactive Learning Environments, 29(1), 142-163. doi:10.1080/10494820.2018.1558257

- Muñoz-Martínez, Y., Gárate-Vergara, F., \& MarambioCarrasco, C. (2021). Training and Support for Inclusive Practices: Transformation from Cooperation in Teaching and Learning. Sustainability, 13(5), 1-17. https://ideas.repec.org/a/gam/jsusta/v13y2021i5p2583 -d507695.html

- $\quad$ Pinho, C., Franco, M., \& Mendes, L. (2021). Application of innovation diffusion theory to the E-learning process: higher education context. Education and Information Technologies, 26(1), 421-440. doi:10.1007/s10639-02010269-2

- $\quad$ Rodriguez, S., Monreal, T., \& Howard, J. (2020). “It's about hearing and understanding their stories": Teacher empathy and socio-political awareness toward newcomer undocumented students in the New Latino South. Journal of Latinos and Education, 19(2), 181-198. doi:10.1080/15348431.2018.1489812

- $\quad$ Ryan, R. M., \& Deci, E. L. (2020). Intrinsic and extrinsic motivation from a self-determination theory perspective: Definitions, theory, practices, and future directions. Contemporary Educational Psychology, 61, 101860. doi:10.1016/j.cedpsych.2020.101860

- $\quad$ Stahnke, R., \& Blömeke, S. (2021). Novice and expert teachers' situation-specific skills regarding classroom management: What do they perceive, interpret and suggest? Teaching and Teacher Education, 98, 103243. doi:10.1016/j.tate.2020.103243

- Tan, O. S. (2021). Problem-based learning innovation: Using problems to power learning in the 21st century. Singapore: Thomson Learning Asia.

- Tria, J. Z. (2020). The COVID-19 pandemic through the lens of education in the Philippines: The new normal. International Journal of Pedagogical Development and Lifelong Learning, 1(1), 2-4. doi:10.30935/ijpdll/8311

- Warrier, U., John, M., \& Warrier, S. (2021). Leveraging emotional intelligence competencies for sustainable development of higher education institutions in the new normal. FIIB Business Review, 10(1), 62-73. doi:10.1177/2319714521992032

- Wieselmann, J. R., Dare, E. A., Ring-Whalen, E. A., \& Roehrig, G. H. (2020). "I just do what the boys tell me": Exploring small group student interactions in an integrated STEM unit. Journal of Research in Science Teaching, 57(1), 112-144. doi:10.1002/tea.21587 
Innovare Journal of Education, Vol 9, Issue 6, 2021, 7-15

- Willingham, D. T. (2021). Why don't students like school?: A cognitive scientist answers questions about how the mind works and what it means for the classroom. John Wiley \& Sons.
- Yeh, Y. C., Hsu, W. C., \& Yastrubinskiy, E. (2021). Decomposing the influences of aesthetic experience processes on creativity learning through various consciousness interventions. Thinking Skills and Creativity, 39, 100756. doi:10.1016/j.tsc.2020.100756 